Printed in Nigeria

\title{
Alteration of Plasma Lipid Profile and Atherogenic Indices of Cholesterol Loaded Rats by Tridax Procumbens Linn: Implications for the Management of Obesity and Cardiovascular Diseases
}

\section{Chigozie Jude IKEWUCHI* and Chidinma Catherine IKEWUCHI}

Department of Biochemistry, Faculty of Science, University of Port Harcourt, P.M.B. 5323, Port Harcourt, Nigeria.

Received July 15, 2009

\begin{abstract}
The effect of the administration of $20 \mathrm{mg} / 100 \mathrm{~g}$ aqueous extract of the leaves of Tridax procumbens on the packed cell volume (PCV), daily weight gain, plasma lipid profiles and atherogenic indices of rats fed $1 \mathrm{~g} / 100 \mathrm{~g}$ cholesterol, was investigated. The mean daily weight gain and plasma concentrations of triglyceride, LDL-, VLDL- and total cholesterol, as well as the atherogenic indices [Cardiac Risk Ratio (CRR), Atherogenic Coefficient (AC) and Atherogenic Index of Plasma (AIP)] of the treated animals were all significantly lower $(\mathrm{p}<0.05)$ than those of the test control and control. The PCV and plasma HDL-cholesterol level of the treated animals was significantly higher $(\mathrm{p}<0.05)$ than that of the test control, although lower than that of the control. These results suggest a possible protective role of the extract against the development of cardiovascular diseases, as well as dyslipidemic conditions, whether primary or secondary to diabetes mellitus, hypertension and obesity
\end{abstract}

Keywords: Hypertension, hypocholesterolemia, lipid profile, obesity, Tridax procumbens

*To whom correspondence should be addressed. E-mail: ecoli240733@yahoo.com, okaraonye@ yahoo.com; Tel: +23480337156 


\section{INTRODUCTION}

About $80 \%$ of the world's population depends on plants to treat many common ailments, and $30 \%$ of modern conventional drugs are derived from plant sources. Herbs have been used safely and effectively for many centuries, and are free of most of the side effects associated with synthetic drugs ${ }^{1}$. Tridax procumbens Linn (compositae), a grass commonly found in tropics is traditionally used in the South Eastern and South Western Nigeria, for stopping bleeding, treating diarrhea, malaria and stomachache, and reducing blood pressure $^{2,3}$. Edeoga et al. ${ }^{2}$ demonstrated the hypotensive effect, while Hemalatha $^{4}$ demonstrated the antihepatotoxic and antioxidant defense potential of aqueous extracts of the leaves of Tridax procumbens on rats.

Dyslipidemia is associated with hypertension, diabetes mellitus and obesity, and is one of the major risk factors for the development of cardiovascular disease ${ }^{5-9}$. Therefore, the present study was designed to investigate the effect of aqueous extracts of Tridax procumbens on the plasma lipid profile of cholesterol-loaded rats with a view to finding any possible cue to the molecular basis of its antihypertensive action.

\section{MATERIALS AND METHODS}

\section{Collection of Animals and Preparation of the Leaves}

Albino rats were collected from the animal house of the Department of Biochemistry, University of Port Harcourt, Port Harcourt, Nigeria. The plants were collected from behind the Ofrima Hall Complex of University of Port Harcourt, Port Harcourt, Nigeria. After due identification at the Herbarium of the Department of Plant Science and Biotechnology, University of Port Harcourt, Nigeria, their leaves were collected, rid of dirt, oven dried at $55^{\circ} \mathrm{C}$ and ground into powder. The resultant powder was soaked in boiled distilled water for $12 \mathrm{~h}$, after which the resultant mixture was filtered and the filtrate, hereinafter referred to as the aqueous extract was stored for subsequent use. A known volume of this extract was evaporated to dryness, and the weight of the residue used to determine the concentration of the filtrate, which was in turn used to determine the dose of administration of the extract to the test animals.

\section{Experimental Design and Composition of Diet}

The rats were randomly sorted into three groups of five animals each, so that the average weight difference was $\pm 1.8 \mathrm{~g}$. The animals were individually housed in plastic metabolic cages. After a one-week acclimatization period on guinea growers mash (Bendel Feed and Flour Mills Ltd., Ewu, Nigeria), the treatment commenced and lasted for a week. The test received daily by intragastric gavages, $1 \mathrm{~g} / 100 \mathrm{~g}$ body weight of cholesterol and $20 \mathrm{mg} / 100 \mathrm{~g}$ body weight of the extract; the test-control received daily by intragastric gavages, $1 \mathrm{~g} / 100 \mathrm{~g}$ body weight of cholesterol; while the control group received appropriate volumes of water by the same route. The dosage of administration of the extract was adapted from Bhagwat et $a l^{10}$. The animals were allowed food and water ad libitum. At the end of the treatment period the rats were weighed and anaesthetized by intraperitoneal injection of $5 \mathrm{mg} / \mathrm{kg}$ body weight of 25\% Urethane saline solution. While under anesthesia blood was collected from each rat via heart puncture and transferred into heparin sample bottles after which they were painlessly sacrificed.

\section{Determination of the Plasma Lipid Profiles/Indices}

Plasma total cholesterol (TC), HDLcholesterol (HDLC) and triglyceride (TG) were assayed enzymatically with commercial test kits (Randox Laboratories, Crumlin, England). Plasma LDL-cholesterol was calculated using the Friedewald equation ${ }^{11}$, as follows:

$$
\begin{aligned}
& L D L C=T C-H D L C-T G / 2.2 . \\
& V L D L C=T G / 2.2 .
\end{aligned}
$$

The atherogenic indices were calculated ${ }^{8,12-14}$ as follows:

Cardiac Risk Ratio $(C R R)=T C / H D L C$ Atherogenic Coefficient $(A C)=(T C-$ $H D L C) / H D L C$

Atherogenic Index of Plasma $(A I P)=$ $\log (T G / H D L C)$ 


\section{Statistical Analysis of Data}

All values are quoted as the mean $\pm \mathrm{SD}$. The values of the various parameters for the control, test control and test groups were analyzed for statistical significant differences using the student's $t$-test. $\mathrm{P}<0.05$ was assumed to be significant.

\section{RESULTS}

Table 1 shows the effect of aqueous extracts of Tridax procumbens on the mean daily weight gain and PCV of cholesterol loaded rats. The mean daily weight gain of the test animals was significantly lower $(p<0.05)$ than that of the test control and the control groups. The PCV of the animals in the test group was significantly higher $(p<0.05)$ than that of the test control, and significantly lower than that of the control. The effect of the aqueous extract of Tridax procumbens on plasma lipid profiles of cholesterol loaded rats is shown in Table 2.

The plasma total triglyceride, LDL-, VLDLand total cholesterol levels of the treated animals was significantly lower $(p<0.05)$ than those of the test control and control. The plasma HDL-cholesterol levels of the treated animals was significantly lower $(p<0.05)$ than that of the test control, although significantly lower than that of the control. The atherogenic indices: cardiac risk ratio (CRR), atherogenic coefficient (AC) and atherogenic index of plasma (AIP), of the treated animals was significantly lower $(p<0.05)$ than those of the test control and control animals (Table 3 ).

\section{DISCUSSION}

The PCV of the animals in the test group was significantly higher than that of the test control, and significantly lower than that of the control (Table 1). This implies that the extract significantly protected the animals against the hypercholesterolemia induced lowering of PCV, even though it could not restore it to normal level. Weight loss helps improve and control coronary risk incidence, diabetes mellitus, dyslipidemia, hypertension, obesity and physical functioning ${ }^{15-18}$, and is one of the strategies for increasing low HDL-C levels ${ }^{19}$, as well as improving the insulin resistance ${ }^{18}$. Therefore, the significantly low mean daily weight gain produced by the extract, in the test animals implies that it may be useful in the management of hypertension, obesity and dyslipidemia.

Table 1: Effect of aqueous extract of Tridax procumbens on the PCV and mean daily weight gain of cholesterol loaded rats.

\begin{tabular}{|l|c|c|c|}
\hline Parameter & Control & Test-control & Test \\
\hline PCV (\%) & $40.59 \pm 4.71^{\mathrm{a}}$ & $34.13 \pm 1.12^{\mathrm{b}}$ & $37.26 \pm 2.85^{\mathrm{c}}$ \\
\hline Mean daily weight gain (g/day) & $6.07 \pm 1.92^{\mathrm{a}}$ & $6.71 \pm 1.01^{\mathrm{a}}$ & $4.29 \pm 0.58^{\mathrm{b}}$ \\
\hline
\end{tabular}

Values are means $\pm S D, n=4$ per group. Entries with different superscripts are significantly different at $p<0.05$.

Table 2: Effect of aqueous extract of Tridax procumbens on the plasma lipid profile of cholesterol loaded rats.

\begin{tabular}{|l|c|c|c|}
\hline \multirow{2}{*}{ Parameter } & \multicolumn{3}{|c|}{ Concentration (mmol/L) } \\
\cline { 2 - 4 } & Control & Test-control & Test \\
\hline Plasma triglyceride & $1.81 \pm 0.36^{\mathrm{a}}$ & $3.71 \pm 0.65^{\mathrm{b}}$ & $1.59 \pm 0.69^{\mathrm{a}}$ \\
\hline Plasma total cholesterol & $6.15 \pm 1.05^{\mathrm{a}}$ & $8.18 \pm 0.71^{\mathrm{b}}$ & $6.37 \pm 0.45^{\mathrm{a}}$ \\
\hline Plasma HDL cholesterol & $2.49 \pm 0.02^{\mathrm{a}}$ & $2.21 \pm 0.04^{\mathrm{b}}$ & $2.49 \pm 0.06^{\mathrm{a}}$ \\
\hline Plasma VLDL cholesterol & $0.82 \pm 0.16^{\mathrm{a}}$ & $1.69 \pm 0.30^{\mathrm{b}}$ & $0.72 \pm 0.31^{\mathrm{a}}$ \\
\hline Plasma LDL cholesterol & $2.83 \pm 0.91^{\mathrm{a}}$ & $4.29 \pm 0.63^{\mathrm{b}}$ & $3.16 \pm 0.20^{\mathrm{a}}$ \\
\hline
\end{tabular}

Values are means $\pm S D, n=4$ per group. Entries with different superscripts are significantly different at $p<0.05$.

Table 3: Effect of aqueous extract of Tridax procumbens on the atherogenic indices of cholesterol loaded rats.

\begin{tabular}{|l|c|c|c|}
\hline Parameter & Control & Test-control & Test \\
\hline Cardiac risk ratio & $2.47 \pm 0.43^{\mathrm{a}}$ & $3.89 \pm 0.98^{\mathrm{b}}$ & $2.57 \pm 0.25^{\mathrm{a}}$ \\
\hline Atherogenic coefficient & $1.47 \pm 0.43^{\mathrm{a}}$ & $2.89 \pm 0.98^{\mathrm{b}}$ & $1.57 \pm 0.25^{\mathrm{a}}$ \\
\hline Atherogenic index of plasma & $-0.15 \pm 0.09^{\mathrm{a}}$ & $0.23 \pm 0.16^{\mathrm{b}}$ & $-0.23 \pm 0.18^{\mathrm{a}}$ \\
\hline
\end{tabular}

Values are means $\pm S D, n=4$ per group. Entries with different superscripts are significantly different at $p<0.05$. 
High plasma concentrations of triglyceride is both an independent and synergistic risk factor for cardiovascular diseases ${ }^{8,14,20}$ and is often found in hypertension ${ }^{5}$, abnormal lipoprotein metabolism, obesity, insulin resistance and diabetes mellitus, ${ }^{6,18,20}$. In this study, the extract produced a significantly lower plasma triglyceride level. Another well-established and recognized risk factor for developing atherosclerosis and other cardiovascular diseases is increased plasma total cholesterol level $^{21}$. It is often found in hypertension ${ }^{5}$. It therefore follows that a reduction in plasma total cholesterol level will reduce the risk of cardiovascular diseases. Thus, the significantly lower plasma total cholesterol levels produced by the extract, connotes the ability of the extract to protect against cardiovascular diseases.

High plasma concentrations of LDL and VLDL cholesterol is a risk factor for cardiovascular disease ${ }^{21,22}$ and is often found in diabetes mellitus ${ }^{6,7,9}$, hypertension ${ }^{5}$ and obesity $^{18}$. Decreases in plasma LDL cholesterol have been considered to reduce risk of coronary heart disease ${ }^{7}$. In this study, we observed a significantly lower plasma LDL and VLDL cholesterol levels in the treated animals.

Another major and well-established risk factor for the development of cardiovascular diseases is decreased plasma concentrations of HDL cholesterol $^{7,8,13,22}$. It often accompanies diabetes mellitus ${ }^{6,7,9}$, hypertension ${ }^{5}$, and obesity $^{18}$. Clinical data show that increase in plasma HDL cholesterol concentration decreases cardiovascular risk ${ }^{7,9,13,19}$.

High HDL exerts a protective effect by decreasing the rate of entry of cholesterol into the cell via LDL and increasing the rate of cholesterol release from the $\mathrm{cell}^{23}$ by enhancing reverse cholesterol transport by scavenging excess cholesterol from peripheral tissues followed by esterification through lecithin: cholesterol acyltransferase and delivering it to the liver and steroidogenic organs for subsequent synthesis of bile acids and lipoproteins and eventual elimination from the body ${ }^{19,21}$; and inhibiting the oxidation of LDL as well as the atherogenic effects of oxidized LDL by virtue of its antioxidant ${ }^{19,21,24}$ and anti-inflammatory property ${ }^{21}$.
In this study, the extract produced an increased plasma HDL cholesterol concentration.

Atherogenic indices are powerful indicators of the risk of heart disease: the higher the value, the higher the risk of developing cardiovascular disease and vice versa ${ }^{8,12-14,25}$. In this study, we observed that the extract significantly reduced atherogenic indices CRR, AC and AIP. Low atherogenic indices are protective against coronary heart disease ${ }^{25}$.

In conclusion, our results suggest a possible protective role of the extract against the development of atherosclerosis and coronary heart disease, as well as the dyslipidemic conditions that characterize diabetes mellitus, hypertension, metabolic syndrome and obesity. It also suggests that the extract can help manage the dyslipidemic conditions ${ }^{26}$ that accompany the administration of thiazide diuretics.

\section{REFERENCES}

1. Murray, M.T. (2004) The Healing Power of Herbs, $2^{\text {nd }}$ edition. Gramercy Books, New York. ISBN; 0-517-22321-X

2. Edeoga, H. O., Okwu, D. E. and Mbaebie, B. O. (2005) Phytochemical constituents of some Nigerian medicinal plants. Afr. J. Biotech. 4:685-688.

3. Salahdeen, H. M., Yemitan, O. K. and Alada, A. R. A. (2004) Effect of Aqueous Leaf Extract of Tridax procumbens on Blood Pressure and Heart Rate in Rats. Afr. J. Biomed. Res. 7: 27 - 29.

4. Hemalatha, R. (2008) Anti-hepatotoxic and anti-oxidant defense potential of Tridax procumbens. Int. J. Green Pharm. 2:164-169.

5. Zicha, J., Kunes, J. and Devynck, M. A. (1999) Abnormalities of membrane function and lipid metabolism in hypertension: a review. Am. J. Hypertens. 12: 315-331.

6. Franz, M.J., Bantle, J.P., Beebe, C.A., Brunzell, J.D., Chiasson, J.L., Garg, A., Holzeister, L.A., Hoogwerf, B., MayerDavies, E., Mooradian, A.D., Purnell, J.Q. and Wheeler, M. (2002) EvidenceBased Nutrition Principles and Recommendations for the Treatment and Prevention of Diabetes and Related Complications. Dabetes Care 25: 148-198.

7. Rang, H. P., Dale, D. M., Ritter, J. M. 
and Moore, P. K. (2005) Pharmacology. $5^{\text {th }}$ ed. Elsevier: India. ISBN: 81-8147917-3.

8. Martirosyan, D. M., Miroshnichenko, L. A., Kulokawa, S. N., Pogojeva, A. V. and Zoloedov, V. I. (2007) Amaranth oil application for heart disease and hypertension. Lipids Health Dis. 6:1.

9. Shen, G.X. (2007) Lipid Disorders in Diabetes Mellitus and Current Management. Curr. Pharmaceut. Analys. 3: $17-24$.

10. Bhagwat, D. A., Killedar S. G. and Adnaik, R. S. (2008) Antidiabetic activity of Leaf Extract of Tridax procumbens. Int. J. Green Pharm. 2: 126-128.

11. Friedewald, W. T., Levy, R. I. and Friedrickson, D. S. (1972) Estimation of the concentration of low-density lipoprotein cholesterol in plasma, without use of the preparative ultracentrifuge. Clin. Chem., 18: 499-502.

12. Brehm, A., Pfeiler, G., Pacini, G., Vierhapper, H., and Roden, M. (2004) Relationship between Serum Lipoprotein Ratios and Insulin Resistance in Obesity. Clin. Chem. 50: 2316-2322.

13. Frohlich, J. and Dobiásová, M. (2003). Fractional Esterification Rate of Cholesterol and Ratio of Triglycerides to HDL-Cholesterol Are Powerful Predictors of Positive Findings on Coronary Angiography. Clin. Chem. 49: 1873-1880

14. Dobiásová, M. (2004) Atherogenic Index of Plasma [log(triglyceride/HDLCholesterol)]: Theoretical and Practical Implications. Clin. Chem., 50: 1113-1115.

15. Reisin, E., Able, R. and Modan, M. (1978) Effect of weight loss without salt restriction in the reduction of blood pressure in overweight hypertensive patients. N. Engl. J. Med. 298:1-6.

16. Trussell, K. C., Hinnen, D., Gray, P., Drake-Nisly, S. A., Bratcher, K. M., Ramsey, H. and Early, J. (2005) Case Study: Weight Loss Leads to Cost Savings and Improvement in Metabolic Syndrome. Diabetes Spectrum 18: 77-79.

17. Bantle, J. P., Wylie-Rosett, J., Albright, A. L., Apovian, C. M., Clark, N. G., Franz, M. J., Hoogwerf, B. J., Lichtenstein, A. H., Mayer-Davis, E., Mooradian, A. D., and Wheeler, M. L. (2006) Nutrition Recommendations and Interventions for Diabetes-2006: A position statement of the American Diabetes Association. Diabetes Care 9:2140-2157.

18. Krauss, R. M., Blanche, P. J., Rawlings, R. S., Fernstrom, H. S. and Williams, $P$. T. (2006) Separate effects of reduced carbohydrate intake and weight loss on atherogenic dyslipidemia. Am. J. Clin. Nutr. 83:1025-31.

19. Assmann, G. and Gotto, A. M. Jr. (2004) HDL Cholesterol and Protective Factors in Atherosclerosis. Circulation 109[suppl III]:III-8-III-14.

20. McBride, P. E. (2007) Triglycerides and Risk for Coronary Heart Disease. JAMA 298: 336-338.

21. Ademuyiwa, O., Ugbaja, R. N., Idumebor, F. and Adebawo, O. (2005) Plasma lipid profiles and risk of cardiovascular disease in occupational lead exposure in Abeokuta, Nigeria. Lipids Health Dis. 4:19.

22. Lichtennstein, A. H., Appel, L. J., Brands, M., Carnethon, M., Daniels, S., Franch, H. A., Franklin, B., KrisEtherton, P., Harris, W. S., Howard, B., Karanja, N., Lefevre, M., Rudel, L., Sacks, F., Van Horn, L., Winston, M. and Wylie-Rosett, J. (2006) Summary of American Heart Association Diet and Lifestyle Recommendations Revision 2006. Arterioscler. Thromb. Vasc. Biol. 26:2186-2191.

23. Marcel. Y. L., Vezina, C., Teng, B. and Snidermann, A. (1980) Transfer of cholesterol esters between human high density lipoprotein and triglyceride rich lipoproteins controlled by plasma protein factor. Atherosclerosis 35: 127-133

24. Brunzell, J. D., Davidson, M., Furberg, C. D., Goldberg, R. B., Howard, B. V., Stein, J. H., and Witztum, J. L. (2008) Lipoprotein Management in Patients With Cardiometabolic Risk: Consensus Conference Report From the American Diabetes Association and the American College of Cardiology Foundation. J. Am. Coll. Cardiol. 51: 1512-1524.

25. Usoro, C. A. O., Adikwuru, C. C., Usoro, I. N. and Nsonwu, A. C. (2006) Lipid Profile of Postmenopausal Women in Calabar, Nigeria. Pak. J. Nutr. 5: 79-82.

26. Salvetti, A. and Ghiadoni, L. (2006) Thiazide Diuretics in the Treatment of Hypertension: An Update. J. Am. Soc. Nephrol. 17: S25-S29 